\title{
Virtual electricity retailer for residents under single electricity pricing environment
}

\author{
Zhe WANG ${ }^{1}$, Yang LI $^{1}{ }^{1}$, Yunwei SHEN ${ }^{1}$, Lei ZHOU ${ }^{1}$, \\ Chen WANG ${ }^{1}$
}

\begin{abstract}
Various residential electricity pricing strategies provide diverse methods for calculating consumption costs. Due to the existence of electricity company monopolies and single residential electricity pricing systems, residents of certain areas have no option but to accept the electricity pricing offered to them. Based on local residential electricity pricing strategies, a virtual electricity retailer (VER) mechanism is put forward. The proposed VER mechanism includes a pricing package plan (PPP), a consumption-based plan, an add-on plan, and an exclusive plan. A PPP optimization pricing model was established to maximize VER profits when taking into account income, allowances from sponsors, expenditures and customer savings. Finally, payment processes were designed under a fixed pricing system and a time-of-use pricing environment. This case study shows the impact of PPPs and the allowance and demonstrates that the model helps customers save electricity while maximizing VER profits.
\end{abstract}

CrossCheck date: 27 December 2016

Received: 29 August 2016/ Accepted: 27 December 2016/Published online: 20 February 2017

(C) The Author(s) 2017. This article is published with open access at Springerlink.com

$\triangle$ Yang LI

li_yang@seu.edu.cn

Zhe WANG

bigtimewang3168@sina.com

Yunwei SHEN

liliansyw@163.com

Lei ZHOU

zhouleiseu@gmail.com

Chen WANG

jzhbg19920824@sohu.com

1 School of Electrical Engineering, Southeast University, Nanjing 210096, China
Keywords Virtual electricity retailer, Residential electricity pricing, Time-of-use pricing, Consumption saving

\section{Introduction}

Residential electricity pricing strategies can be developed with several goals: cost reflectivity, equity between customers, predictability of expenditure for customers, and stability of revenue for electricity companies. These goals may compete with each other. Current residential electricity pricing strategies includes fixed pricing, time-of-use (TOU) pricing, critical peak pricing (CPP), real-time pricing (RTP) and tiered pricing (TP) [1, 2].

Fixed pricing only reflects the operating cost of the power system without considering the demand side [3]. On the contrary, price-based demand response (DR) programs are a form of demand-side management (DSM) based on electricity price signals and provide users with different electricity pricing strategies [4]. The purpose of DR is to adapt the load curve by adjusting customers' electrical behaviors [5]. TOU, CPP and RTP are the main electricity pricing strategies in DR. In TOU pricing schemes, electricity prices vary during different periods, according to a regular daily pattern [6-8], and peak periods cost more than off-peak periods. Under TOU pricing schemes, CPP mechanisms set a higher rate than the peak rate during periods when it is more difficult to meet customer load $[9,10]$. The electricity price in real-time pricing (RTP) varies with time according to a signal that reflects electricity system conditions [11-13]. TP is a mechanism for DSM to help customers adjust electricity consumption. On the basis of consumption, TP sets the electricity price at different levels [14]. 
Local electricity retailers offer different electricity pricing strategies to attract customers who wish to save money or obtain other benefits. Relevant studies focus on the commercial methods of electricity retail. References [15] and [16] researched load aggregators connecting customers with electricity retailers who can shift loads and make profits. Reference [17] researched principal-agent theory used in TOU pricing contract and the results showed the successful application of the DR theory. In [18], modeling showed that an agent-based retail electricity market increases efficiency, reduces operational costs and provides consumers with more alternatives. Reference [19] studied bilateral contracting and coalitions of end-use customers in multi-agent retail energy markets and concluded that forward contracts are more favorable to customers.

China launched a new round of power system reforms in 2015, and related documents issued with these reforms encourage the introduction of new electricity retailers $[20,21]$. While many new electricity retailers have been founded [22, 23], based on the potential capacity for consumption reduction, electricity retailers prefer to select industrial and commercial customers for DR programs, and residents are generally ignored [24, 25].

Residential electricity pricing in most provinces of China is mainly applied via TOU pricing schemes combined with TP pricing options [26, 27]. In areas where electricity monopolies exist, electricity companies determine residential electricity pricing strategies $[28,29]$, and residents have no opportunity to select electricity retailers. It is thus not possible for such residents to participate in DSM programs apart from TOU pricing and TP offered by the electricity monopolies. These programs are not always effective. As TOU pricing settings and corresponding time periods are unified, some customers cannot avoid incurring extra consumption costs [30]. TP constrains consumption over a long time period. However, TP is not advantageous when several independent residents are sharing a single electricity account [31]. A customer account shared with several residents may incur additional tariffs because it may need to pay more consumption tariffs and higher electricity prices [32]. Furthermore, in fixed price areas, residential customers cannot find suitable DSM programs that offer TOU and TP options [33, 34].

Existing DSM and DR research is mainly about the electricity unit price and the customized pricing strategies that may be used when there are multiple electricity companies sharing the market. When a monopoly electricity company creates a single electricity pricing environment, existing research about customized pricing strategies is not applicable. With the popularity of internet applications and the development of internet finance, it is more convenient for customers to pay electricity bills online [35]. This creates an opportunity to allow residents to participate in DR schemes, and a virtual electricity retailer (VER) mechanism to achieve this is proposed in this paper. A VER is an electricity agency for residential customers that has the following key features.

1) A VER provides differentiated electricity pricing for residential customers in a single electricity pricing environment. It combines principal-agent theory and contract theory [36-38]. In areas characterized by monopolies and without an open electricity market, such as China, a VER offers customers a choice of electricity contracts and agents for their electrical supply. VER offers customers options for residential electricity plan contracts that the local electricity company cannot provide. These contracts allow customers to purchase VER plans as they want. In turn, the VER pays electricity bills to the electricity company for customers in accordance with their metered consumptions. Since the average residential electricity price offered by a VER is lower than that offered by a local electricity company, it is more attractive for customers to sign VER contracts.

2) A VER creates profit opportunities without reducing the electricity company's profits. Under a single electricity pricing environment, the proposed trading mechanism of VER is a new pattern to sale electricity in plans without breaking current residential electricity transmission and distribution structures. As VER pays electricity fees to the electricity company for customers based on their metered consumption, VER doesn't reduce the electricity company's profits while helping residents to achieve consumption savings. Meanwhile, VER sponsors can earn profits through advising and VER product sales making it a stable capital source which guarantees VER operating processes.

3) A VER is virtual and operates as e-commerce. With the development of the internet and electronic commerce, more and more consumers shop online. E-commerce is applied to all aspects of life through customer applications offering online trading platforms. The operating mode of VERs is $\mathrm{O} 2 \mathrm{O}$ (online to offline) [39, 40]. Current e-commerce in the power industry only allows customers to pay their bills. The term VER includes providing a service to customers with flexible electricity pricing strategies to promote energy consumption efficiency on the basis of reasonable profit. VERs can learn from the successful experiences of other e-commerce initiatives for operating policies and risk mitigation [41, 42].

The remainder of this paper is outlined as follows. Section 2 provides a further description of electricity retailers. The PPP optimization pricing model for VERs 
offering either fixed or TOU pricing are described in Sect. 3. A simulation of the PPP optimization pricing model and an application of two PPPs are presented in Sect. 4. Finally, conclusions and areas for future research are discussed in Sect. 5.

\section{Virtual electricity retailer}

\subsection{VER description}

A VER differs from electricity companies and existing electricity retailers since it is operated as e-commerce and is based on internet finance. Operating on the platform provided by existing electricity supply services, a VER provides residents with flexible electricity pricing options. In areas characterized by single electricity pricing schemes, a VER offers individual residents diverse electricity pricing options and helps customers manage their electricity bills.

A VER offers different contract options to customers, on the basis of existing residential electricity pricing schemes offered by local electricity companies. Customers can choose a VER plan and sign a contract with the VER. Consumption costs are then calculated on the basis of this contract for the duration of the contract period. The VER pays customers electricity bills to the relevant local electricity company based on local electricity pricing schemes.

Figure 1 shows the VER operation process. According to local electricity pricing systems, consumption costs generated through real consumption are equivalent to what an electricity company charges its customers. Customers sign VER contracts and pay charges based on their VER plans. VER agents pay consumption fees to the relevant electricity company. A VER can also deliver incentivebased DR programs, which can help customers reduce consumption and related costs even further.

As a form of e-commerce, the capital resources of a VER include both its assets and sponsorship from interested parties such as product retailers and power plants. A VER provides sponsors with an open platform to advertise their brands. Compared to other products advertised, electricity is a necessary aspect of human life, and all electricity users have opportunities to see electrical product advertisements. To increase product sales, product retailers can also sell products bundled with VER plans. In turn, customers can receive benefits (e.g., consumption savings via VER plans) after purchasing products.

A VER does not rely on sponsorship, though it is very important. Firstly, sufficient funds ensure enough resources for the stable operation of a VER. Besides, as a form of e-commerce based on internet finance, a VER uses the internet platform to attract investment in the operation. Furthermore, adequate funding helps to expand the business scope by designing different types of packages or new discount structures to attract more customers. Finally, under the premise of adequate funding, a VER provides customers with stable electricity package plans to minimise operational risk.

Promotion of VERs is restricted due to institutional issues and traditional practices in China or other areas with a monopolistic electricity pricing environment. It is reasonable to promote VERs through pilot projects that include investigation of the base-line load, the capacity for adapting load, and the willingness of local residential customers to adopt suitable VER plans in the pilot areas. For other areas with organized markets, it is easier to implement VERs because the retailing function is usually included as part of the market structure.

\subsection{VER characteristics and plans}

A VER is virtual, representable, economic, and intermediary. Table 1 presents these key characteristics of a VER.

A VER is virtual in that it does not provide physical supplies and does not generate or distribute electricity. A VER provides services that link electricity companies to customers via VER contracts. Customers still receive electricity from electricity companies. A VER is representative in that it represents customer needs. In essence, a VER is an agency that assists customers with paying their electricity bills. A VER is economic in that it functions based on economic methods. A VER is an intermediary that connects customers to electricity companies.

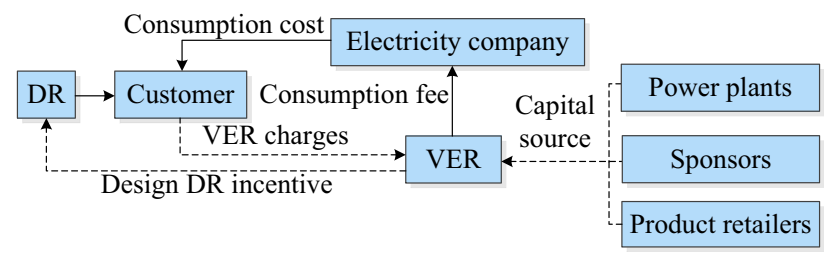

Fig. 1 VER operation process
Table 1 VER characteristics

\begin{tabular}{ll}
\hline Characteristic & Details \\
\hline Virtual & No generation, transmission or distribution \\
Representative & Represents customer demand \\
Economic & Uses economic methods \\
Intermediary & Links customers to electricity companies \\
\hline
\end{tabular}


A VER can supply multiple types of plan: pricing package plans (PPPs), consumption-based plans (CBPs), add-on plans (APs), and exclusive plans (EPs).

Table 2 provides descriptions of the VER plans. Each plan is based on the price of electricity and has unique features.

\subsection{Pricing package plan}

To avoid risks resulting from fluctuating electricity prices, electricity options are used in the electricity market. Electricity options allow holders to trade electricity at a certain price over a certain time period [43]. Holders pay option premiums to secure this right, but not necessarily to exercise this right [44]. Electricity options and related subjects are always used among industries and commercial customers [45], but for residential customers, due to the existence of single electricity pricing schemes in some areas, electricity options cannot be designed or exercised.

The design of a PPP refers to the construction of electricity options is shown in Table 3 . When compared to electricity option theory, the VER is the writer that designs the PPP schemes and residential customers are the holders. The VER offers customers PPPs, which offer certain electricity tariffs for a certain time period. Customers who

Table 2 Descriptions of VER plans

\begin{tabular}{|c|c|}
\hline $\begin{array}{l}\text { VER } \\
\text { plans }\end{array}$ & Description \\
\hline PPP & $\begin{array}{l}\text { Customers prepay for limited electricity. Unused } \\
\text { electricity is not retained after the VER contract } \\
\text { deadline has passed }\end{array}$ \\
\hline CBP & $\begin{array}{l}\text { Customers buy electricity at a lower price than the local } \\
\text { electricity price. However, electricity has a maximum } \\
\text { limit during the VER contract period }\end{array}$ \\
\hline AP & $\begin{array}{l}\text { A less comprehensive version of a PPP. The period of } \\
\text { validity is synchronized with the pricing package plan } \\
\text { that the customer has selected }\end{array}$ \\
\hline EP & $\begin{array}{l}\text { Cash-back opportunities for customers who buy electricity } \\
\text { from a specified brand. EPs constitute the main profit } \\
\text { model used by VERs }\end{array}$ \\
\hline
\end{tabular}

Table 3 Comparisons between electricity options and VER PPP schemes

\begin{tabular}{ll}
\hline Electricity options & PPP \\
\hline Writer & VER \\
Holder & Residential customer \\
Option premium & PPP sale price \\
Exercise price & Electricity \\
Expiry date & Expiry date \\
\hline
\end{tabular}

buy PPPs have the right to consume limited electricity before the expiry date, and excess electricity consumed is charged at a higher electricity price.

The PPPs in VER contracts offer customers a diversity of electricity pricing plans. PPPs are based on the prepaid method and electricity options. After selecting and paying for a PPP, a customer has a certain amount of electricity to use over the outlined contract period. The limits of each PPP are unique and the electricity prices are different. Based on previous consumption costs, customers select the best pricing package plan for them.

In order to attract customers to choose a PPP, the VER offers a discount in electricity price to compete with the electricity company. The discount amount in the PPP is related to sponsorship (allowance), consumption behavior, the electricity limit in PPP and the electricity fee of local electricity company. In addition, it is better to be ensured that the limits of PPPs are suitable for customers' consumption behaviors.

A pricing package plan includes limited electricity for a time period based on a single retail pricing scheme. Compared to local residential electricity pricing schemes, average PPP prices are lower. Customers sign PPP contracts and prepay for limited electricity. VER charges at the end of the customer use period, and each payment has two components: the plan payment and extra charges for usage exceeding the limited electricity specified. Extra charges are higher than the local residential price. The PPP payment scheme is described in Fig. 2.

\subsection{Consumption-based plan}

A CBP in a VER contract is generated based on a specific index. Customers buy electricity at a lower price than the local electricity price. However, a limited amount of electricity is assigned over the VER contract period.

Figure 3 shows the differential electricity pricing scheme applied under a CBP. To maximize electricity sales, an electricity company sells electricity at a preferential price. The VER buys the specified amount of electricity from the electricity company. Accordingly, the VER has the right to sell this electricity. Under a CBP scheme, the VER sets a new electricity price, and the new price is set at a value ranging between the electricity company

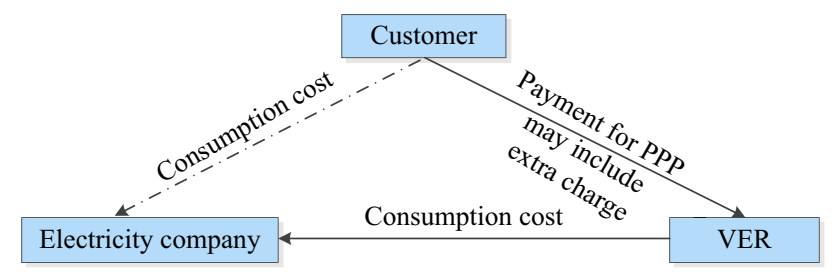

Fig. 2 PPP payment process 


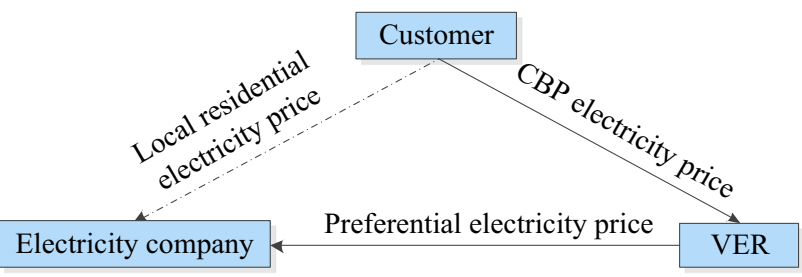

Fig. 3 CBP electricity pricing

purchase price and the local residential electricity price. CBPs place several limitations on customers. Such plans limit individual customer consumption over contract periods. Consumption exceeding the threshold stated in the contract is charged at the local residential electricity price. Typically, CBPs are given as a reward to specific VER customers such as new or long-term customers.

CBPs offer customers a limited amount of electricity at a discounted price. The two main CBP features to discuss are the participant's qualification for a CBP and capital sources available to compensate funding for the discounted price.

VER customers who are qualified to participate in a CBP are selected by the VER. To increase its customer base, a VER can offer new customers a CBP for a limited time period (e.g., 3 months). As a way to attract long-term VER customers, the VER may offer customers a continuing CBP as an incentive-based coupon.

Funding to recuperate the discounted portion of the CBP is obtained in three ways. Based on the given CBP, the VER aggregating a great number of customers can get a preferential price while contracting with the electricity company directly, which compensates for the discount offered to customers. When the preferential price is not accommodated by the electric company, the VER can also afford to compensate for the CBP cost from its profits or by receiving funding from its direct sponsors.

\subsection{Add-on plan}

To avoid incurring extra consumption costs by exceeding the electrical consumption specified by a VER plan, which may be a PPP or a CPB, customers may extend their VER services by purchasing an AP. An AP is a less comprehensive version of a PPP. APs offer the same features as typical plans but are redesigned according to the prevailing electricity and selling price. The average electricity price offered through APs may differ from that offered through PPPs.

\subsection{Exclusive plan}

An EP provides discounts on consumption costs for specified uses of electrical products. To sell more products, electrical manufacturers sponsor EPs for new buyers of electrical products. New buyers can sign a VER's EP contract, which provides discounts based on the consumption costs of new electrical product buyers. EPs list electricity brands for customers, and customers may also sign other VER plans.

EPs constitute the main profit model used by VERs. According to our profit analysis of PPPs, VERs can earn profits through either sponsors or customers. Customer electricity usage behavior is uncontrolled and, therefore, customers can pay higher consumption fees through VERs, but sponsors serve as the main funding resource. Sponsor funding is mainly used to finance VER operation, design, and expansion plans.

For customers and sponsors, EPs also offer unique advantages. For VER customers, the availability of more EPs results in better opportunities to reduce consumption costs. EPs also influence customer decisions regarding whether to buy new electrical products. The cost of purchasing such products is not the only element to be considered, and consumption costs and savings from EPs can provide customers with cost-performance benefits.

For sponsors, a VER serves as a new platform for attracting customers. VER platforms such as websites and apps can provide electrical manufacturers and sponsors with an advertising channel. EPs also assist sponsors with marketing products to create new opportunities to retail their products bundled with EPs. As electricity is an essential product, the expenditure of electricity is unavoidable, and VER customers may wish to manage their expenditure when they select a PPP. Their consumption status may be checked in real time via different channels such as websites or mobile apps. Hence the exposure of advertisements on the VER platform is potentially very high.

\section{VER application}

Since PPPs can readily be promoted on a large scale with a low barrier to entry for new customers, and they can be implemented independently of external influences such as electricity company discounts for CBPs or brand sponsorships for EPs, PPPs will be modelled in this paper to demonstrate that the VER model is viable in fixed and TOU pricing environments.

\subsection{PPP design for fixed pricing environment}

PPP profits are related to customer plan usage rates, plan parameter settings and allowances from VER sponsors. The objective of the PPP optimized pricing model is to maximize VER profits given by: 
$\max V_{\mathrm{P}}=V_{\mathrm{C} \text {,sum }}+A-V_{\text {Local,sum }}$

where $V_{\mathrm{P}}$ is the VER's profit and based on plan usage levels; $V_{\mathrm{C}, \text { sum }}$ is the sum of the VER charges to the customer; $A$ is the allowance from sponsors; $V_{\text {Local,sum }}$ is the sum of the consumption charges based on the local residential electricity price.

1) Income

$$
\begin{aligned}
& V_{\mathrm{C}, \text { sum }}=C_{\mathrm{ppp}, \text { sum }}+C_{\mathrm{Extra}, \text { sum }} \\
& C_{\mathrm{ppp}, \text { sum }}=\sum_{i=1}^{n} C_{\mathrm{ppp}, i}=\sum_{i=1}^{n} s_{i} P_{\mathrm{ppp}} E_{\mathrm{ppp}}
\end{aligned}
$$

where $C_{\mathrm{ppp}, \text { sum }}$ is the sum of PPP charges; $C_{\text {Extra,sum }}$ is the sum of extra charges for consumption exceeding the PPP limit; $n$ is the number of customers; $i$ is the number of customers; $C_{\mathrm{ppp}, i}$ is the PPP charge for customer $i$; $s_{i}$ indicates whether customer $i$ signs the contract, taking a value of 0 or $1 ; P_{\mathrm{ppp}}$ is the PPP electricity price; $E_{\mathrm{ppp}}$ is the electricity limit in the PPP.

Customers can decide whether to sign the contracts on the basis of their expected price.

$s_{i}= \begin{cases}1, & \eta_{i} \geq P_{\mathrm{ppp}} \\ 0, & \eta_{i}<P_{\mathrm{ppp}}\end{cases}$

where $\eta_{i}$ is the threshold PPP electricity price that the customer is willing to pay.

$$
\begin{aligned}
C_{\text {Extra }, \text { sum }} & =\sum_{i=1}^{n} C_{\text {Extra }, i} \\
& =\sum_{i=1}^{n} s_{i} \times \max \left(E_{\text {Real }, i}-E_{\mathrm{ppp}}, 0\right) \times P_{\text {Extra }}
\end{aligned}
$$

where $C_{\mathrm{Extra}, i}$ is the charge for customer $i$ 's extra consumption exceeding the PPP limit; $E_{\text {Real }, i}$ is the real consumption of customer $i$ during the PPP contract period; $P_{\text {Extra }}$ is the electricity price for extra consumption that exceeds the PPP limit.

\section{2) Allowance}

The PPP allowance is the capital guaranteeing that VER customers will the pay the electricity company the electricity fee based on the local electricity pricing model. It is assumed that this allowance will need to be paid for a certain percentage of users to allow the VER to provide reliable financial support to the PPP operation.

$A=\partial \times \sum_{i=1}^{n} s_{i}\left(P_{\text {Local }}-P_{\mathrm{ppp}}\right) \times E_{\mathrm{ppp}}$

where $\partial$ is the PPP allowance rate which represents the proportion of the customers who need allowance; $P_{\text {Local }}$ is the local residential electricity price. It is assumed that there are $\partial$ of customers needing allowance.
3) Expenditure

$V_{\text {Local }, \text { sum }}=\sum_{i=1}^{n} V_{\text {Local }, i}=\sum_{i=1}^{n} s_{i} E_{\text {Real }, i} P_{\text {Local }}$

where $V_{\text {Local }, i}$ is the cost of customer $i$ 's consumption based on the local residential electricity price.

\subsection{Modelling customer savings}

Customer savings relate to the PPP usage rate.

$C_{\mathrm{S}, i}=V_{\mathrm{Local}, i}-V_{\mathrm{C}, i}$

$\alpha_{i}=\frac{E_{\mathrm{Real}, i}}{E_{\mathrm{ppp}}}$

$\beta=\frac{P_{\mathrm{ppp}}}{P_{\text {Local }}}$

$\gamma=\frac{P_{\text {Extra }}}{P_{\text {Local }}}$

where $C_{\mathrm{S}, i}$ is the savings of customer $i ; V_{\mathrm{C}, i}$ is the VER charged to customer $i ; \alpha_{i}$ is the fraction of the PPP electricity limit that is used by customer $i$; $\beta$ is the ratio of PPP price to local electricity price; $\gamma$ is the ratio of extra consumption price to local electricity price.

Based on plan usage levels, two scenarios were considered in the VER profit analysis.

1) Usage rate less than 1

When $\alpha_{i}<1$, customer $i$ avoids paying extra charges. When $\alpha_{i}<1, C_{\mathrm{Extra}, i}$ is ignored. $C_{\mathrm{S}, \alpha_{i}<1}$ depends on $C_{\mathrm{ppp}, i}$ and $V_{\text {Local }, i}$.

$C_{\mathrm{S}, \alpha_{i}<1}=V_{\mathrm{Local}, i}-C_{\mathrm{PPP}, i}=\left(1-\frac{\beta}{\alpha_{i}}\right) \times E_{\mathrm{Real}, i} P_{\mathrm{Local}}$

As $E_{\mathrm{Real}, i}$ and $P_{\mathrm{Local}}$ are positive, if $C_{\mathrm{S}, \alpha_{i}<1}>0$, then $\frac{\beta}{\alpha}$ should be less than 1 . Thus, when the PPP parameter settings satisfy $\beta<\alpha_{i}<1$, customer $i$ will not pay the consumption fee.

2) Usage rate greater than 1

When $\alpha_{i}>1$, customer $i$ pays extra charges to compensate for the consumption that exceeds the package limit. $C_{\mathrm{S}, \alpha_{i}>1}$ depends on $C_{\mathrm{ppp}, i}, C_{\mathrm{Extra}, i}$ and $V_{\mathrm{Local}, i}$.

$$
\begin{aligned}
C_{\mathrm{S}, \alpha_{i}>1} & =V_{\mathrm{Local}, i}-C_{\mathrm{PPP}, i}-C_{\mathrm{Extra}, i} \\
& =\left[\alpha_{i}(1-\gamma)+(\gamma-\beta)\right] \times \frac{1}{\alpha_{i}} \times E_{\text {Real }, i} P_{\text {Local }}
\end{aligned}
$$

As $E_{\text {Real }, i}$ and $P_{\text {Local }}$ are positive, if $C_{\mathrm{S}, \alpha_{i}>1}>0$, then $\alpha_{i}(1-\gamma)+(\gamma-\beta)$ should be positive. Therefore, when the PPP parameter settings satisfy $\frac{\gamma-\beta}{\gamma-1}>\alpha_{i}>1$, customer $i$ will not pay the consumption fee. 


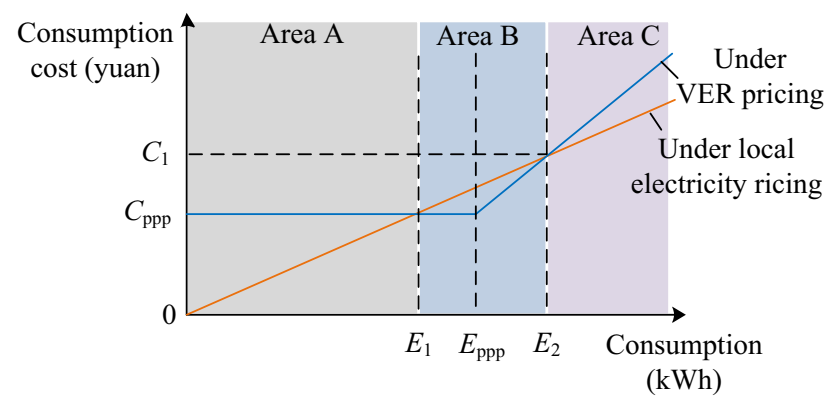

Fig. 4 PPP consumption cost curves in a fixed pricing system

Customer consumption savings are dependent on the VER plan parameters and customers' ability to manage their consumption. Our analysis is based on the schematic diagram shown in Fig. 4. The blue line refers to the consumption cost of customers under VER pricing and the orange line shows standard local electricity pricing. $\left(E_{1}, C_{\mathrm{ppp}}\right)$ and $\left(E_{2}, C_{1}\right)$ denote the crossover points at which consumption costs in the two pricing schemes are the same.

At $\left(E_{1}, C_{\mathrm{ppp}}\right), E_{1}=E_{\text {Real }}=\beta E_{\mathrm{ppp}}$, and at $\left(E_{2}, C_{1}\right)$, $E_{2}=E_{\text {Real }}=E_{\text {ppp }}(\gamma-\beta) /(\gamma-1)$. Area B in Fig. 4 denotes customer consumption savings achieved through the VER plan. Customers occupying area $\mathrm{A}$ or area $\mathrm{C}$ will pay more than local electricity company prices. Thus, when $E_{\text {Real }} \in$ $\left(\beta E_{\mathrm{ppp}},(\gamma-\beta) /(\gamma-1) E_{\mathrm{ppp}}\right)$ under PPP pricing, customers will save consumption fees.

\subsection{PPP design in TOU pricing environment}

For a PPP under TOU pricing TOU, electricity usage has two components: the off-peak load period and the peak load period. VER charges are based on the following parameters.

1) Electricity limit

$E_{\mathrm{ppp}}^{\mathrm{TOU}}=E_{\mathrm{ppp}, \mathrm{v}}^{\mathrm{TOU}}+E_{\mathrm{ppp}, \mathrm{p}}^{\mathrm{TOU}}$

where $E_{\mathrm{ppp}}^{\mathrm{TOU}}$ is the electricity limit in TOU PPP; $E_{\mathrm{ppp}, \mathrm{v}}^{\mathrm{TOU}}$ is the electricity limit in TOU PPP for the off-peak load period; $E_{\mathrm{ppp}, \mathrm{p}}^{\mathrm{TOU}}$ is the electricity limit in TOU PPP for the peak load period.

2) VER charges

$$
\begin{aligned}
V_{\mathrm{C}, \mathrm{sum}}^{\mathrm{TOU}} & =V_{\mathrm{C}, \mathrm{v}, \mathrm{sum}}^{\mathrm{TOU}}+V_{\mathrm{C}, \mathrm{p}, \mathrm{sum}}^{\mathrm{TOU}}=\sum_{i=1}^{n} V_{\mathrm{C}, i}^{\mathrm{TOU}} \\
& =\sum_{i=1}^{n}\left(V_{\mathrm{C}, \mathrm{v}, i}^{\mathrm{TOU}}+V_{\mathrm{C}, \mathrm{p}, i}^{\mathrm{TOU}}\right)
\end{aligned}
$$

where $V_{\mathrm{C}, \text { sum }}^{\mathrm{TOU}}$ is sum of the VER charges incurred by all TOU customers; $V_{\mathrm{C}, \mathrm{v}, \mathrm{sum}}^{\mathrm{TOU}}$ is the sum of consumption costs for off-peak load period consumption by TOU customers; $V_{\mathrm{C}, \mathrm{p} \text {,sum }}^{\mathrm{TOU}}$ is the sum of consumption costs for peak load period consumption by TOU customers; $V_{\mathrm{C}, i}^{\mathrm{TOU}}$ is the consumption cost incurred by TOU customer $i$; $V_{\mathrm{C}, \mathrm{v}, i}^{\mathrm{TOU}}$ is the consumption cost incurred by TOU customer $i$ for off-peak load period consumption; $V_{\mathrm{C}, \mathrm{p}, i}^{\mathrm{TOU}}$ is the consumption cost incurred by TOU customer $i$ for peak load period consumption.

3) Off-peak load period

$$
\begin{aligned}
V_{\mathrm{C}, \mathrm{v}, \mathrm{sum}}^{\mathrm{TU}}= & C_{\mathrm{ppp}, \mathrm{v}, \mathrm{sum}}^{\mathrm{TOU}}+C_{\mathrm{Extra}, \mathrm{v}, \mathrm{sum}}^{\mathrm{TOU}}-V_{\mathrm{Local}, \mathrm{v}, \mathrm{sum}}^{\mathrm{TOU}} \\
C_{\mathrm{ppp}, \mathrm{v}, \mathrm{sum}}^{\mathrm{TOU}} & =\sum_{i=1}^{n} C_{\mathrm{ppp}, \mathrm{v}, i}^{\mathrm{TOU}}=n P_{\mathrm{ppp}, \mathrm{v}}^{\mathrm{TOU}} E_{\mathrm{ppp}, \mathrm{v}}^{\mathrm{TOU}} \\
C_{\mathrm{Extra}, \mathrm{v}, \mathrm{sum}}^{\mathrm{TOU}} & =\sum_{i=1}^{n} C_{\mathrm{Extra}, \mathrm{v}, i}^{\mathrm{TOU}} \\
& =\sum_{i=1}^{n} \max \left(E_{\mathrm{Real}, \mathrm{v}, i}^{\mathrm{TOU}}-E_{\mathrm{ppp}, \mathrm{v}}^{\mathrm{TOU}}, 0\right) P_{\mathrm{Extra}, \mathrm{v}}^{\mathrm{TOU}} \\
V_{\mathrm{Local}, \mathrm{v}, \mathrm{sum}}^{\mathrm{TOU}} & =\sum_{i=1}^{n} V_{\mathrm{Local}, \mathrm{v}, i}^{\mathrm{TOU}}=\sum_{i=1}^{n} E_{\mathrm{Real}, \mathrm{v}, i}^{\mathrm{TOU}} P_{\mathrm{Local}, \mathrm{v}}^{\mathrm{TOU}}
\end{aligned}
$$

where $C_{\mathrm{ppp}, \mathrm{v} \text {,sum }}^{\mathrm{TOU}}$ is off-peak load period consumption that the VER charges all TOU customers for via a PPP; $C_{\mathrm{Extra}, \mathrm{v}, \text { sum }}^{\mathrm{TOU}}$ is the extra consumption exceeding the PPP's electricity limit for the off-peak load period that the VER charges all TOU customers for via a PPP; $V_{\text {Local,v.sum }}^{\text {TOU }}$ is the off-peak load period consumption that the local electricity company charges all TOU customers for; $C_{\mathrm{ppp}, \mathrm{v}, i}^{\mathrm{TOU}}$ is the off-peak load period consumption that the VER charges TOU customer $i$ for via a PPP; $P_{\mathrm{ppp}, \mathrm{v}}^{\mathrm{TOU}}$ is the off-peak load period electricity price through the TOU PPP; $C_{\mathrm{Extra}, \mathrm{v}, i}^{\mathrm{TOU}}$ is the consumption exceeding the PPP's electricity limit of the off-peak load period that the VER charges TOU customer $i$ for via a PPP; $E_{\mathrm{Real}, \mathrm{v}, i}^{\mathrm{TOU}}$ is the real off-peak load period consumption level of TOU customer $i$; $P_{\mathrm{Extra}, \mathrm{v}}^{\mathrm{TOU}}$ is the electricity price for extra consumption exceeding the PPP TOU electricity limit for the off-peak load period; $V_{\mathrm{Local}, \mathrm{v}, i}^{\mathrm{TOU}}$ is the off-peak load period consumption that the local electricity company charges TOU customer $i$ for; $P_{\mathrm{Local}, \mathrm{T}}^{\mathrm{TOU}}$ is the off-peak load period electricity price charged by the local electricity company.

4) Peak load period

$$
\begin{aligned}
& V_{\mathrm{C}, \mathrm{p}, \mathrm{sum}}^{\mathrm{TOU}}=C_{\mathrm{ppp}, \mathrm{p}, \mathrm{sum}}^{\mathrm{TOU}}+C_{\mathrm{Extra}, \mathrm{p}, \mathrm{sum}}^{\mathrm{TOU}}-V_{\mathrm{Local}, \mathrm{p}, \mathrm{sum}}^{\mathrm{TOU}} \\
& C_{\mathrm{ppp}, \mathrm{p}, \mathrm{sum}}^{\mathrm{TOU}}=\sum_{i=1}^{n} C_{\mathrm{ppp}, \mathrm{p}, i}^{\mathrm{TOU}}=n P_{\mathrm{ppp}, \mathrm{p}}^{\mathrm{TOU}} E_{\mathrm{ppp}, \mathrm{p}}^{\mathrm{TOU}}
\end{aligned}
$$




$$
\begin{aligned}
C_{\text {Extra, } \mathrm{p}, \mathrm{sum}}^{\mathrm{TOU}} & =\sum_{i=1}^{n} C_{\text {Extra, } \mathrm{p}, i}^{\mathrm{TOU}} \\
& =\sum_{i=1}^{n} \max \left(E_{\text {Real }, \mathrm{p}, i}^{\mathrm{TOU}}-E_{\mathrm{ppp}, \mathrm{p}}^{\mathrm{TOU}}, 0\right) P_{\text {Extra }, \mathrm{p}}^{\mathrm{TOU}} \\
V_{\text {Local }, \mathrm{p}, \text { sum }}^{\mathrm{TOU}} & =\sum_{i=1}^{n} V_{\text {Local }, \mathrm{p}, i}^{\mathrm{TOU}}=\sum_{i=1}^{n} E_{\text {Real }, \mathrm{p}, i}^{\mathrm{TOU}} P_{\text {Local }, \mathrm{p}}^{\mathrm{TOU}}
\end{aligned}
$$

where $C_{\text {ppp,p,sum }}^{\mathrm{TOU}}$ is the peak load period consumption that the VER charges all TOU customers for via a PPP; $C_{\text {Extra,p,sum }}^{\text {TOU }}$ is the extra consumption exceeding the PPP's electricity limit for the peak load period that the VER charges all TOU customers for via a PPP; $V_{\text {Local,p,sum }}^{\mathrm{TOU}}$ is the peak load period consumption that the local electricity company charges all TOU customers for; $C_{\mathrm{ppp}, \mathrm{p}, i}^{\mathrm{TOU}}$ is the peak load period consumption that the VER charges TOU customers $i$ for via a PPP; $P_{\mathrm{ppp}, \mathrm{p}}^{\mathrm{TOU}}$ is the peak load period electricity price set through the TOU PPP; $C_{\mathrm{Extra}, \mathrm{p}, i}^{\mathrm{TOU}}$ is the consumption exceeding the PPP's electricity limit of the peak load period that the VER charges TOU customers $i$ for via a PPP; $E_{\mathrm{Real}, \mathrm{p}, i}^{\mathrm{TOU}}$ is the real peak load period consumption level of TOU customer $i$; $P_{\text {Extra,p }}^{\mathrm{TOU}}$ is the electricity price for extra consumption exceeding the PPP TOU electricity limit for the peak load period; $V_{\mathrm{Local}, \mathrm{p}, i}^{\mathrm{TOU}}$ is the peak load period consumption that the local electricity company charges TOU customer $i$ for; $P_{\text {Local }, \mathrm{p}}^{\mathrm{TOU}}$ is the peak load period electricity price set by the local electricity company

\section{5) Clip peak load incentive threshold}

For peak load clipping in TOU pricing, a VER design and include incentive-based DRs where if a customer's peak period consumption levels are less than $35 \%$ of the PPP electricity (sum of the off-peak and peak period), the off-peak period electricity price is discounted by $15 \%$.

$\theta_{i}=\frac{E_{\mathrm{Real}, \mathrm{p}, i}^{\mathrm{TOU}}}{E_{\mathrm{ppp}}^{\mathrm{TOU}}}$

$V_{\mathrm{C}, i}^{\mathrm{TOU}}=\left\{\begin{array}{l}V_{\mathrm{C}, \mathrm{v}, i}^{\mathrm{TOU}}+V_{\mathrm{C}, \mathrm{p}, i}^{\mathrm{TOU}} \quad \text { if } \theta_{i}>35 \% \\ 85 \% \times V_{\mathrm{C}, \mathrm{v}, i}^{\mathrm{TOU}}+V_{\mathrm{C}, \mathrm{p}, i}^{\mathrm{TOU}} \quad \text { if } \theta_{i} \leq 35 \%\end{array}\right.$

where $\theta_{i}$ is the ratio of peak load period consumption for customer $i$ in the TOU electricity.

6) Customer savings

$C_{\mathrm{S}, i}^{\mathrm{TOU}}=V_{\mathrm{Local}, \mathrm{v}, i}^{\mathrm{TOU}}-V_{\mathrm{C}, i}^{\mathrm{TOU}}$

where $C_{\mathrm{S}, i}^{\mathrm{TOU}}$ is the reduction in consumption of TOU customer $i$.

\section{Simulation results and discussion}

\subsection{PPP optimization in fixed pricing environment}

According to historical data on the consumption of 10,000 users, consumption follows a uniform distribution between 50 and $300 \mathrm{kWh}$. Accordingly, the VER modelled in this paper is based on 4 PPP categories with different electricity limits. The electricity limit of 30 days in these plans is set to $100,150,200$, and $250 \mathrm{kWh}$, and each plan is available to 2500 users. Customers' eligibility for these plans is based on their consumption level, with plan 1 offering 50-150 kWh, plan 2 offering 100-200 kWh, plan 3 offering $150-250 \mathrm{kWh}$ and plan 4 offering 200$300 \mathrm{kWh}$. The threshold PPP price they are prepared to pay $\eta_{i}$ is assumed to follow a normal distribution that ranges from 0.3 to $0.5 \mathrm{yuan} / \mathrm{kWh}$. The PPP allowance rate is assumed to be 0.7 . Consumption exceeding the electricity limit is charged at 1 yuan/kWh. The fixed electricity price of the local electricity company is $0.5 \mathrm{yuan} / \mathrm{kWh}$. The simulation was implemented on MATLAB2014b, and the objective function was optimized by the commercial optimization software CPLEX12.1.

\section{1) PPP electricity prices}

Table 4 shows the PPP electricity price optimization results. The mean value is 0.3650 yuan $/ \mathrm{kWh}$.

\section{2) Customer participation rates}

Figure 5 shows the participation rates of PPP customers. The black segments refer to the proportions of the customers who do not purchase PPPs. As illustrated in Fig. 5, the majority of customers (up to 89\%) select PPPs.

\section{3) VER profit analysis}

Table 5 presents a detailed account of the VER profit results. As the electricity limit in the PPP increases, the VER profits decrease.

According to the explanation shown in Fig. 4 above, users in area B should save money from consumption charges. Figs. 6 and 7 show the status of customers for different PPP electricity limits. As the PPP electricity use

Table 4 PPP electricity price optimization results

\begin{tabular}{ll}
\hline Plan & PPP electricity price $(\mathrm{yuan} / \mathrm{kWh})$ \\
\hline 1 & 0.3490 \\
2 & 0.3638 \\
3 & 0.3616 \\
4 & 0.3856 \\
\hline
\end{tabular}


increases, more area B users achieve greater consumption savings.

\section{4) Allowance}

In order to study the impact of allowance on VER profit, different allowance coefficients, from 0 to 0.9 are set in the case simulation.

Table 6 shows allowance coefficient effects on PPP outcomes. As more allowances for PPPs are provided, the difference between the PPP electricity price and local electricity price $(0.5$ yuan $/ \mathrm{kWh})$ becomes larger, a larger variety of PPPs becomes available to customers. Figure 8 illustrates that the VER can still be profitable with a PPP with no allowance. VER profits and participation rates increase as the allowance coefficient increases (Figs. 8, 9).

\subsection{PPP case study in a fixed pricing environment}

\subsubsection{Base experimental group (Group 1)}

The local electricity price for residents is set at 0.5 yuan/ $\mathrm{kWh}$, and the PPP price is set at 73 yuan. The latter price includes a consumption limit of $200 \mathrm{kWh}$ per month. Consumption exceeding this value is charged at 1 yuan/ kWh.

Group 1 is the base experimental group of the VER, which generates 100 electricity bills for local residents over a 30-day period. The units used are composed of individually generated random values of $160-300 \mathrm{kWh}$. The new

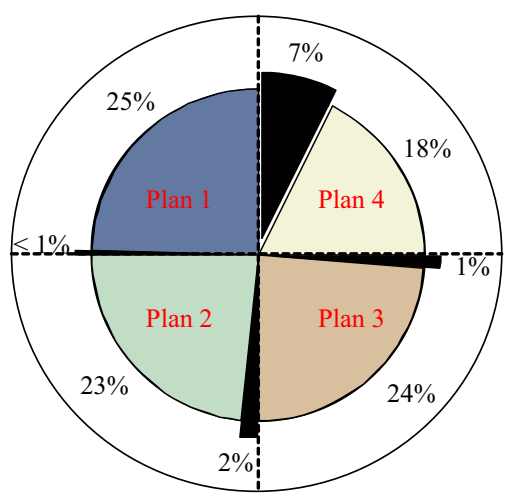

Fig. 5 PPP customer participation rates consumption cost of the PPP of the VER contract is calculated and is compared to consumption savings based on normal charges.

Table 7 shows the consumption savings for the base experiment. The average consumption saving for individual customers is 12.84 yuan. The total savings of all customers are valued at 1284 yuan. For Group 1, the maximum consumption saving for an individual customer reaches 27 yuan. However, the maximum extra payment due from customers is 19 yuan. Customers can save on consumption costs via the VER plan, but not all customers are able to save. When a customer does not use all of the PPP or exceeds the PPP limit, so that he or she falls outside area B in Fig. 4, the customer pays more than usual.

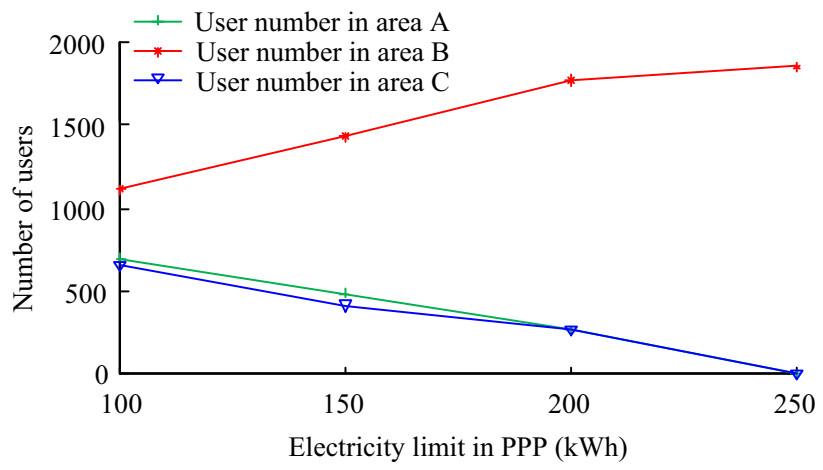

Fig. 6 User numbers in areas A, B, C of Fig. 4 versus the electricity limit in PPP plans

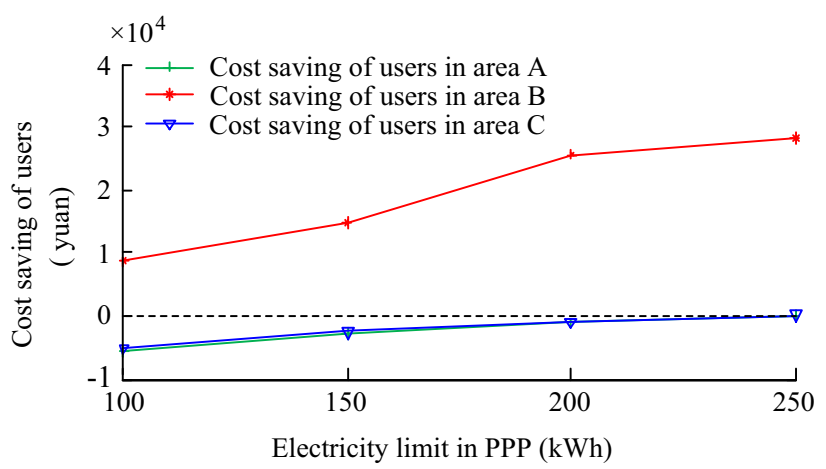

Fig. 7 User electricity cost savings versus the electricity limit in PPP plans

Table 5 Detailed VER profit results

\begin{tabular}{|c|c|c|c|c|c|}
\hline Parameters & Plan 1 & Plan 2 & Plan 3 & Plan 4 & Total \\
\hline PPP charges (yuan) & 85864.74 & 127190.27 & 171749.92 & 170164.31 & 554969.25 \\
\hline Charges of extra consumption (yuan) & 38272.50 & 37368.56 & 42232.59 & 22199.83 & 140073.47 \\
\hline Allowance (yuan) & 25994.68 & 33344.31 & 46025.06 & 35322.48 & 140686.53 \\
\hline Standing charges (yuan) & 121800.35 & 173707.90 & 237425.82 & 220619.09 & 753553.15 \\
\hline VER profits (yuan) & 28331.57 & 24195.24 & 22581.75 & 7067.53 & 82176.10 \\
\hline
\end{tabular}


Table 6 Allowance coefficient effects on PPP design

\begin{tabular}{|c|c|c|c|c|c|}
\hline $\begin{array}{l}\text { Allowance } \\
\text { coefficient }\end{array}$ & $\begin{array}{l}\text { Electricity price in plan } 1 \\
\text { (yuan/kWh) }\end{array}$ & $\begin{array}{l}\text { Electricity price in plan } 2 \\
\text { (yuan/kWh) }\end{array}$ & $\begin{array}{l}\text { Electricity price in plan } 3 \\
\text { (yuan/kWh) }\end{array}$ & $\begin{array}{l}\text { Electricity price in plan } \\
4 \text { (yuan/kWh) }\end{array}$ & $\begin{array}{l}\text { Numbers of } \\
\text { available plan }\end{array}$ \\
\hline 0.0 & 0.3753 & - & - & - & 1 \\
\hline 0.1 & 0.3880 & 0.4162 & - & - & 2 \\
\hline 0.2 & 0.3852 & 0.4132 & - & - & 2 \\
\hline 0.3 & 0.3702 & 0.3873 & 0.4013 & - & 3 \\
\hline 0.4 & 0.3630 & 0.3802 & 0.3907 & - & 3 \\
\hline 0.5 & 0.3630 & 0.3742 & 0.3789 & - & 3 \\
\hline 0.6 & 0.3623 & 0.3667 & 0.3697 & 0.4054 & 4 \\
\hline 0.7 & 0.3490 & 0.3638 & 0.3616 & 0.3856 & 4 \\
\hline 0.8 & 0.3465 & 0.3531 & 0.3589 & 0.3695 & 4 \\
\hline 0.9 & 0.3389 & 0.3438 & 0.3468 & 0.3526 & 4 \\
\hline
\end{tabular}

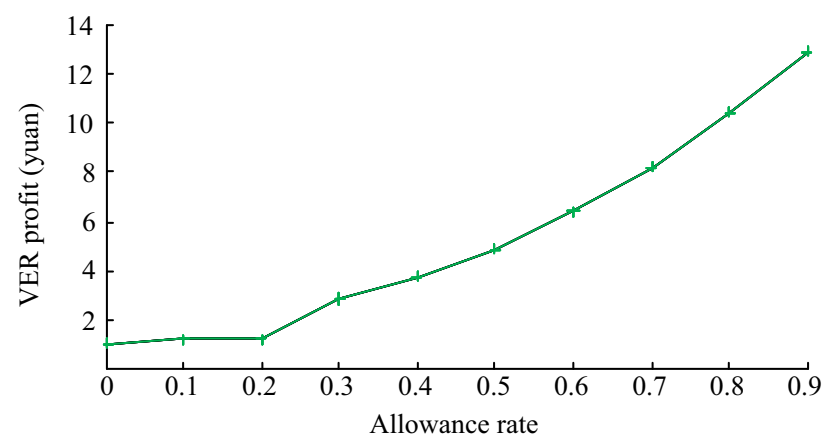

Fig. 8 Influence of allowance coefficient on VER profits

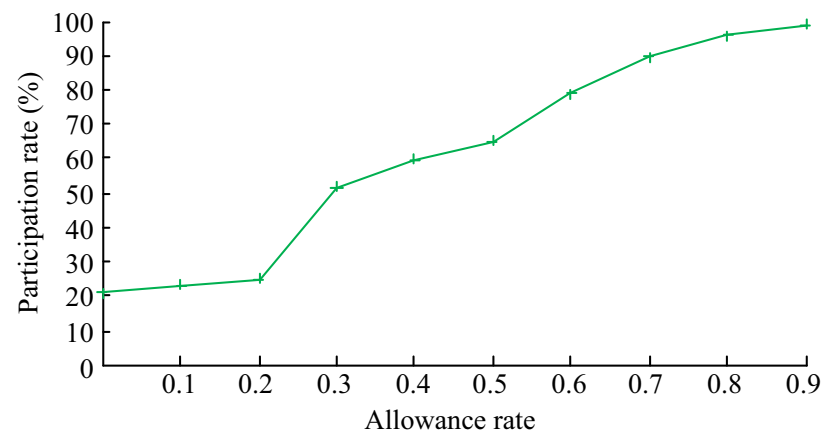

Fig. 9 Influence of allowance coefficient on participation rates

\subsubsection{Effects of electricity and extra electricity prices on simulation results}

Based on the consumption savings of Group 1, the number of units $(\mathrm{kWh})$ and standing charge (yuan/kWh) are maintained while changing the extra electricity price. In the following subsection, 8 groups are investigated.

Group 1: VER base experimental group.

Group 2-Group 8: change in the extra electricity price.

Consumption savings results (Groups 1-8) are presented in Table 8. Compared to the results of Group 1, decreased extra electricity prices (Group 2-3) generate more consumption savings for customers. Increasing the extra electricity price (Group 4-8) causes customers to make more payments.

\subsubsection{Add-on plan}

The AP is designed for customers to decrease extra payments incurred upon exceeding the PPP limit. If the usage rate in the PPP exceeds a value of 1 due to higher electricity prices, then customers may pay a higher consumption fee. According to (13), the threshold for Group 1 is $254 \mathrm{kWh}$. Group 9 includes 17 customers of Group 1

Table 7 Detailed PPP results of Group 1

\begin{tabular}{lccrc}
\hline Parameters & Max of individual & Min of individual & Average of all & Total \\
\hline Consumption savings (yuan) & 27 & -19 & 12.84 & 1284 \\
Units used (kWh) & 200 & 292 & 207.68 & 20768 \\
Standing charge (yuan) & 100 & 146 & 103.84 & 10384 \\
Electricity limit (kWh) & 200 & 200 & 200 & 20000 \\
Extra electricity price (yuan/kWh) & 1 & 1 & 1 & 91.01 \\
VER charge (yuan) & 73 & 164.8 & 9101 \\
\hline
\end{tabular}


Table 8 Effects of extra electricity prices on simulation results

\begin{tabular}{|c|c|c|c|c|c|c|c|c|}
\hline \multirow[t]{2}{*}{ Parameters } & \multicolumn{8}{|c|}{ Group } \\
\hline & 1 & 2 & 3 & 4 & 5 & 6 & 7 & 8 \\
\hline Electricity limit (kWh) & 200 & 200 & 200 & 200 & 200 & 200 & 200 & 200 \\
\hline Extra electricity price (yuan/kWh) & 1 & 0.8 & 0.9 & 1.1 & 1.2 & 1.3 & 1.4 & 1.5 \\
\hline Average VER charge (yuan) & 91 & 87.4 & 89.2 & 92.8 & 94.6 & 96.4 & 98.2 & 100 \\
\hline Average consumption savings (yuan) & 12.8 & 16.4 & 14.6 & 11 & 9.2 & 7.4 & 5.6 & 3.8 \\
\hline
\end{tabular}

Table 9 Detailed PPP results of Group 9

\begin{tabular}{lll}
\hline Parameters & Without AP & With AP \\
\hline Average units used (kWh) & 270 & 270 \\
Average standing charge (yuan) & 135 & 135 \\
Electricity limit (kWh) & 200 & 220 \\
Extra electricity price (yuan/kWh) & 1 & 1 \\
Average VER charge (yuan) & 143.2 & 132 \\
Average consumption savings (yuan) & -8.11 & 3.13 \\
Total consumption savings (yuan) & -137.8 & 53.28 \\
\hline
\end{tabular}

who have used more than $254 \mathrm{kWh}$ units, meaning that the AP can offer these customers savings so that they can avoid incurring higher penalty fees for exceeding the PPP usage limits.

For Group 9, if it is assumed that all 17 customers have signed an AP contract and that AP sales are set at 8.76 yuan, which includes an electricity limit of $20 \mathrm{kWh}$ for the current month, then PPP customers are only offered a onetime qualification point at which to purchase the AP.

Table 9 compares the consumption savings of Group 9. The results show that with the AP, customers benefit more from consumption savings than they do without the AP.

\subsection{PPP design in TOU pricing environment}

According to the existing TOU pricing scheme used in Jiangsu, China, the local TOU off-peak load period (23:007:00) electricity price for residents is set at $0.35 \mathrm{yuan} / \mathrm{kWh}$ and the peak load period (7:00-19:00) electricity price is set at 0.55 yuan/kWh. The TOU PPP price is set at 79.98 yuan for 30 days, and this includes a consumption limit of $200 \mathrm{kWh}(120 \mathrm{kWh}$ for the off-peak load and $80 \mathrm{kWh}$ for the peak load). Table 10 shows TOU PPP electricity pricing. For the TOU PPP, the off-peak load electricity price is set at 0.3225 yuan/kWh and the peak load electricity price is set at 0.5115 yuan $/ \mathrm{kWh}$. Consumption exceeding the TOU PPP limit is charged at 0.3675 yuan/kWh during the off-peak load period and at 0.8184 yuan/kWh during the peak load period. When a customer's ratio of peak load consumption $\theta \leq 35 \%$, a $15 \%$ discount is applied to the
Table 10 TOU PPP electricity pricing

\begin{tabular}{lccl}
\hline Electricity pricing & $P_{\mathrm{ppp}, \mathrm{v}}^{\mathrm{TOU}}$ & $P_{\text {Extra, } \mathrm{v}}^{\mathrm{TOU}}$ & if $\theta \leq 35 \%$ \\
\hline Off-peak period (yuan/kWh) & 0.3255 & 0.3675 & 0.2767 \\
\hline Electricity pricing & $P_{\mathrm{ppp}, \mathrm{p}}^{\mathrm{TOU}}$ & $P_{\text {Extra,p }}^{\mathrm{TOU}}$ & if $\theta \leq 35 \%$ \\
\hline Peak period (yuan/kWh) & 0.5115 & 0.8184 & 0.3124 \\
\hline
\end{tabular}

electricity price during the off-peak load period, meaning that the off-peak load period price of the TOU PPP decreases to 0.2767 yuan $/ \mathrm{kWh}$ and the price for exceeding the TOU PPP limit is 0.3124 yuan/kWh.

\subsection{Electricity charges for TOU PPP scenarios}

Scenario 1: off-peak load period consumption does not exceed the TOU PPP limit

When consumption during the off-peak load period is fixed and the value reaches the maximum off-peak load limit of $120 \mathrm{kWh}$, the VER charges and savings for an individual resident are dependent on the peak load period consumption level.

For the TOU PPP, the peak load period consumption incentive discount is disregarded, and electricity charges that correspond to peak load period consumption levels between 69.055 and $102.161 \mathrm{kWh}$ are lower than local electricity prices.

After applying the peak load period consumption incentive discount, the TOU PPP price is $15 \%$ less at 74.484 yuan for customers consuming less than $70 \mathrm{kWh}$ during peak periods. Customers incurring peak period consumption levels of between 59.06 and $70 \mathrm{kWh}$ can thus save via the TOU PPP.

Figure 10 shows TOU pricing consumption cost curves for Scenario 1. Under the parameter settings shown for Scenario 1, TOU PPP customers who consume peak period electricity levels of between 59.06 and $102.161 \mathrm{kWh}$ should save money.

Scenario 2: off-peak load consumption exceeds the TOU PPP limit 


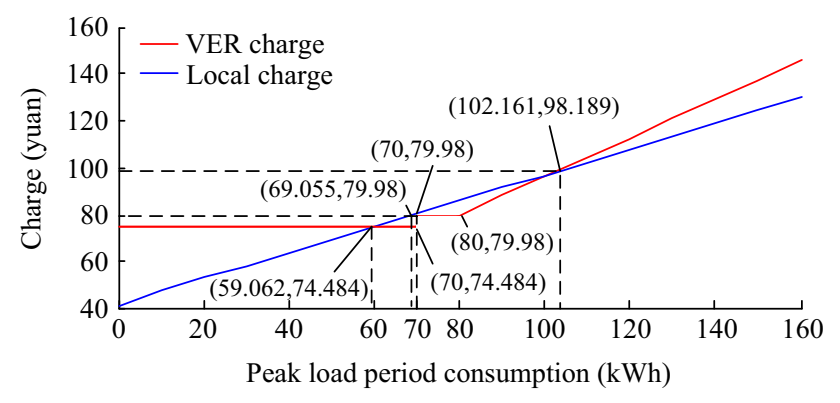

Fig. 10 Consumption cost curves of TOU pricing (off-peak load consumption is set at $120 \mathrm{kWh}$ )

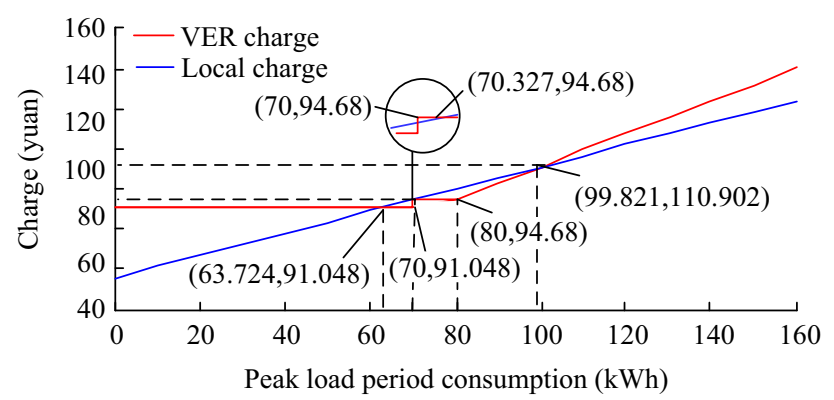

Fig. 11 Consumption cost curves of TOU pricing (off-peak load consumption is set at $160 \mathrm{kWh}$ )

When consumption during the off-peak load period is fixed and the value is higher than the maximum off-peak load limit at $160 \mathrm{kWh}$, the VER charges and consumption savings for an individual resident are dependent on the peak load period consumption level.

For the TOU PPP, when the peak load period consumption incentive discount is disregarded, electricity charges that correspond to peak load period consumption levels of between 70.327 and $99.821 \mathrm{kWh}$ are lower than local electricity prices.

After applying the peak load period consumption incentive coupon discount, the TOU PPP price is 15\% less at 94.68 yuan for customers incurring peak period consumption levels of less than $70 \mathrm{kWh}$. Customers with peak period consumptions of between 63.724 and $70 \mathrm{kWh}$ can save via the TOU PPP.

Figure 11 presents consumption cost curves of TOU pricing for Scenario 2. Under the parameter settings of Scenario 2, TOU PPP customers who consume peak period electricity levels of between 63.724 and $70 \mathrm{kWh}$ and between 70.327 and $99.821 \mathrm{kWh}$ will save money.

\section{Conclusion}

This paper proposes a VER mechanism for residents of single electricity pricing environments including a PPP, a $\mathrm{CBP}$, an AP and an EP. The PPP optimisation pricing model was presented as a way to maximize VER profits in consideration of income, allowance, expenditure and customer saving levels.

PPP design was demonstrated under fixed pricing and time-of-use pricing environments using simulated data price and customer data. The simulation results illustrate the consequent positive effects on customer savings and the effectiveness of the model while considering PPP settings as well as allowances.

Notwithstanding the contributions of this paper, areas for improvement will be addressed in our future work. VER development should focus on EPs because this is potentially the main source of revenue for VERs. To boost sales volumes, sponsors should endorse VER plans to attract more customers. VERs can receive funds from sponsors, alleviate financial pressures on their operations, and design more plans for customers. Customers can in turn be provided with more options in selecting optimal electricity pricing strategies so that they can save money. This should create a triple-win scenario for VERs, their customers, and their sponsors.

To avoid this risk, the VER operator should review customer credit ratings before VER contracts are signed. Furthermore, the VER operator should consider credit risk when designing payment methods in further research.

Acknowledgements This work was supported by National Natural Science Foundation of China (No. 51277028) and National High Technology Research and Development Program of China (863 Program) (No. 2015AA050401).

Open Access This article is distributed under the terms of the Creative Commons Attribution 4.0 International License (http:// creativecommons.org/licenses/by/4.0/), which permits unrestricted use, distribution, and reproduction in any medium, provided you give appropriate credit to the original author(s) and the source, provide a link to the Creative Commons license, and indicate if changes were made.

\section{References}

[1] Albadi MH, El-Saadany EF (2007) Demand response in electricity markets: an overview . In: Proceedings of the 2007 IEEE Power Engineering Society General Meeting, Florida, USA, 24-28 June 2007, 5 pp

[2] Faruqui A, Sergici S (2010) Household response to dynamic pricing of electricity: a survey of 15 experiments. J Regul Econ 38(2): 193-225

[3] Faruqui A, Eakin K (2000) Pricing in competitive electricity markets. Kluwer Academic Publishers, Dordrecht

[4] Palensky P, Dietrich D (2011) Demand side management: demand response, intelligent energy systems, and smart loads. IEEE Trans Ind Inf 7(3):381-388

[5] Gellings CW (1993) Demand-side management planning. Pennwell Corporation, Oklahoma

[6] Datchanamoorthy S, Kumar S, Ozturk Y et al (2011) Optimal time-of-use pricing for residential load control. In: Proceedings 
of the 2011 IEEE international conference on smart grid communications, Brussels, Belgium, 17-20 Oct 2011, pp 375-380

[7] He YQ, David AK (1997) Time-of-use electricity pricing based on global optimization for generation expansion planning. In: Proceedings of the 1997 fourth international conference on advances in power system control, operation and management, Hong Kong, China, 11-14 Nov 1997, pp 668-673

[8] Celebi E, Fuller JD (2012) Time-of-use pricing in electricity markets under different market structures. IEEE Trans Power Syst 27(9):1170-1181

[9] Li F, Wang Z (2011) Critical peak pricing tariff design for mass consumersin Great Britain. In: Proceedings of the 2011 IEEE power and energy society general meeting, Detroit, USA, 24-28 July 2011, pp 1-6

[10] Wang Z, Paranjape R, Sadanandet A et al (2013) Residential demand response: an overview of recent simulation and modeling applications. In: Proceedings of the 26th annual IEEE Canadian conference on electrical and computer engineering, Regina, Canada, 5-8 May 2013, pp 1-6

[11] Qian LP, Zhang YJA, Huang J et al (2013) Demand response management via real-time electricity price control in smart grids. IEEE J Sel Areas Commun 31(7):1268-1280

[12] Conejo AJ, Morales JM, Baringo L (2010) Real-time demand response model. IEEE Trans Smart Grid 1(3):236-242

[13] Pang Q, Su P, Sun B (2012) Real-time price based home appliances intelligent control. In: Proceedings of the 2012 third international conference on digital manufacturing and automation, Guilin, China, 31 July-2 Aug 2012, pp 634-637

[14] Li Y, Luo Q, Song Y et al (2012) Study on the tier tap determining of basic residential electricity consumption based on demand response. In: Proceedings of the 2012 Asia-Pacific power and energy engineering conference, Shanghai, China, 27-29 March 2012, pp 1-5

[15] Gao C, Li Q, Li H et al (2013) Methodology and operation mechanism of demand response resources integration based on load aggregator. Autom Electr Power Syst 37(17):78-86

[16] Chen C, Kishore S, Wang Z et al (2012) How will demand response aggregators affect electricity markets? A cournot game analysis. In: Proceedings of the 2012 5th international symposium on communications, control and signal processing, Rome, Italy, 2-4 May 2012, pp 1-6

[17] Chen S, Love HA, Liu CC (2016) Optimal opt-in residential time-of-use contract based on principal-agent theory. IEEE Trans Power Syst 31(6):4415-4426

[18] Yu J, Zhou JZ, Yang JJ et al (2004) Agent-based retail electricity market: modeling and analysis. In: Proceedings of the 2004 international conference on machine learning and cybernetics, Shanghai, China, 26-29 Aug 2004, pp 95-100

[19] Lopes F, Algarvio H, Ilco C et al (2013) Agent-based simulation of retail electricity markets: bilateral contracting with demand response. In: Proceedings of the 2013 24th international workshop on database and expert systems applications, Prague, Czech Republic, 26-30 Aug 2013, pp 194-198

[20] Code 9 (2015). In: The State Council of the People's Republic of China. http://www.cec.org.cn/zhuanti/2015nianzhuanti/2015 dianlitizhigaigezaichufa/yaowen/2015-06-18/139371.html. Accessed 15 Mar 2016

[21] Six Measures for Power System Reform (2015). In: The State Council of the People's Republic of China. http://www.gov.cn/ xinwen/2015-11/30/content_5018218.htm. Accessed 15 Mar 2016

[22] GWEC (2015) Global wind energy council. In: Global wind energy council. http://www.gwec.net/chinas-electricity-marketreform/. Accessed 15 Aug 2016

[23] Cheng W (2016) Power retail pilots open in Guangzhou, Chongqing. In: China energy storage alliance. http://en.cnesa.org/ featured-stories/2016/3/2/power-retail-pilots-open-in-guangzhouchongqing. Accessed 2 Mar 2016

[24] Wang B, Li Y, Gao C (2009) Demand side management outlook under smart grid infrastructure. Autom Electr Power Syst 33(20): 17-22

[25] Dong M (2014) Demand response effect evaluation considering time-of-use price. Dissertation, North China Electric Power University

[26] Chen J, Wang Z (2013) Trends of increasing block pricing in electricity-summary fo the conference on theory and policy of China's increasing block pricing in electricity. China Ind Econ 12:71-77

[27] Li C, Ma T, Wang J (2014) Analysis of long-term effect and dymamic adjustment for elctric power industry step tariff reform in China. Shanxi Electr Power 42(10):28-32

[28] Hussin NS, Abdullah MP, Ali AIM et al (2014) Residential electricity time of use (ToU) pricing for Malaysia. In: Proceedings of the 2014 IEEE conference on energy conversion, Johor Bahru, Malaysia, 13-14 Oct 2014, pp 429433

[29] Muzmar MAR, Abdullah MP, Hassan MY et al (2015) Time of use pricing for residential customers case of Malaysia. In: Proceedings of the 2015 IEEE student conference on research and development, Kuala Lumpur, Malaysia, 13-14 Dec 2015, pp 589-593

[30] Zeng S, Li J, Ren Y (2008) Research of time-of-use electricity pricing models in China: a survey. In: Proceedings of the 2008 IEEE international conference on industrial engineering and engineering management, Singapore, 8-11 Dec 2008, pp 2191-2195

[31] Sun L, Wang J, Yang W et al (2015) Study on the residents tiered pricing model after the sale of electricity liberalization. In: Proceedings of the 2015 IEEE 12th international conference on ubiquitous intelligence and computing and 2015 IEEE 12th international conference on autonomic and trusted computing and 2015 IEEE 15th international conference on scalable computing and communications and its associated workshops, Beijing, China, 10-14 Aug 2015, pp 1402-1406

[32] Code ZJSP42-2015-0049 (2015). In: The People's Government of Zhejiang Province. http://www.zhejiang.gov.cn/art/2015/11/ 23/art_13929_250965.html. Accessed 15 Mar 2016

[33] Nazar NSM, Abdullah MP, Hassan MY et al (2012) Implementation in monopolized electricity market. In: Proceedings of the 2012 IEEE student conference on research and development, Penang, Malaysia, 5-6 Dec 2012, pp 178-181

[34] Li M, Wan Q (2011) Study on TOU price implantation effect on Huainan resident. In: Proceedings of the 2011 international conference on computer distributed control and intelligent environmental monitoring, Hunan, China, 19-20 Feb 2011, pp 2221-2224

[35] Alipay (2016). In: Alipay payment. https://jiaofei.alipay.com/ jiaofei.htm. Accessed 1 Mar 2016

[36] Weibull J (1995) Evolutionary game theory. MIT Press, Cambridge

[37] Laffont J, Martimort D (2002) The theory of incentives: the principal-agent model. Princeton University Press, Princeton

[38] Bolton P, Dewatripont M (2004) Contract theory. MIT Press, Cambridge

[39] Weng CI, Lu HP, Wei PS (2016) Did you LINE today? Strategies for creating LINE online to offline customer experiences. In: Proceedings of the 2016 49th hawaii international conference on system sciences, Hawaii, USA, 5-8 Jan 2016, pp 2136-2145

[40] Zhang S, Lee JH (2015) The effect of O2O on behavioral intention and preference. ICIC Exp Lett Part B Appl 6(4):1189-1195 
[41] Liu Q (2015) China's Internet financial ecosystem overview. In: Proceedings of the 2015 international conference on logistics, informatics and service sciences, Barcelona, Spain, 27-29 July 2015, pp 1-4

[42] Hu Y, Zhao S (2011) A case study of online retail innovation system on Alibaba Taobao. In: Proceedings of the 2010 international conference on E-Business and E-Government, Guangzhou, China, 7-9 May 2011, pp 224-227

[43] Zhang X, Wang X (2005) Survey of financial markets for electricity. Autom Electr Power Syst 29(20):1-9

[44] Wang R (2010) Review of application research on options in electricity market. In: Proceedings of the 2010 international conference on mechanic automation and control engineering, Wuhan, China, 26-28 June 2010, pp 5227-5230

[45] Yu G, Zhou YH, He JH (2007) Establishing an electric power futures forward and option market suited to China's situation. Electr Power Constr 28(1):71-73

Zhe WANG received his B.S. degree in Electrical Engineering and Automation from Shanghai University of Electric Power, Shanghai, China, in 2011 and the M.S. degree in Electronic and Electrical Engineering at University of Strathclyde, Glasgow, UK, in 2012. He is currently working towards the Ph.D. degree at the School of Electrical Engineering in Southeast University, Nanjing. His current research interests include electricity market and demand side management.
Yang LI is now a professor at the School of Electrical Engineering in Southeast University, Nanjing, China. From June 1998 to June 1999, he was a visiting scholar at Aichi University of Technology, Japan. During November 2001-January 2002 and July 2002-October 2002, he was a vising scholar at Hong Kong University. His current research interests include power system's operation, electricity market and demand side management.

Yunwei SHEN received her B.S. degree in Electrical Engineering from Southeast University, Nanjing, China, in 2014. She is currently working towards the Ph.D. degree at the School of Electrical Engineering in Southeast University, Nanjing. Her current research interests include power market and demand side management.

Lei ZHOU received his B.S. degree in Electrical Engineering from Southeast University, Nanjing, China, in 2012. He is currently working towards the Ph.D. degree at the School of Electrical Engineering in Southeast University, Nanjing. His current research interests include electricity market and demand side management.

Chen WANG received his B.S. degree in Electrical Engineering from Sichuan University, Sichuan, China, in 2014. He is currently working toward the master degree at the School of Electrical Engineering in Southeast University, Nanjing. His current research interests include distribution planning and demand side management. 